\title{
Optimal Conductor Selection in Radial Distribution Systems for Productivity Improvement Using Genetic Algorithm
}

\author{
Mahdi Mozaffari Legha" ${ }^{* 1, a}$, Hassan Javaheri ${ }^{2, b}$, Mohammad Mozaffari Legha ${ }^{3, c}$ \\ ${ }^{1}$ Department of Electrical Engineering, University of Javid, Jiroft, Iran \\ ${ }^{2}$ Department of Electrical Engineering, University of Javid, Jiroft, Iran \\ ${ }^{3}$ Departments of Electronic Engineering, Kerman Branch, Islamic Azad University, Iran \\ Mahdi_mozaffari@ymail.com ${ }^{\mathrm{a}}$; javaheri.msc@gmail.comb ${ }^{\mathrm{b}}$; Mozaffari50@gmail.com ${ }^{\mathrm{c}}$
}

\begin{abstract}
Development of distribution systems result in higher system losses and poor voltage regulation. Consequently, an efficient and effective distribution system has become more urgent and important. Hence proper selection of conductors in the distribution system is important as it determines the current density and the resistance of the line. This paper examines the use of different evolutionary algorithms, genetic algorithm (GA), to optimal branch conductor selection in planning radial distribution systems with the objective to minimize the overall cost of annual energy losses and depreciation on the cost of conductors and reliability in order to improve productivity.

Furthermore, The Backward-Forward sweep iterative method was adopted to solve the radial load flow analysis. Simulations are carried out on 69-bus radial distribution network using GA approach in order to show the accuracy as well as the efficiency of the proposed solution technique.
\end{abstract}

Keywords: Distribution system optimization, reliability, genetic algorithm, radial distribution systems, Backward-Forward sweep, Loss Reduction.

\section{Introduction}

The main objective of an electrical distribution system (EDS) is providing a reliable and cost-effective service to consumers with considering power quality within standard ranges. Thus, it is necessary to properly plan the EDS and thus evaluate several aspects such as, new equipment installation cost, equipment utilization rate, and quality of service, reliability of the distribution system and loss minimization, considering an increase of system loads, and newly installed loads for the planning horizon [1]. There are several parameters to be taken into account to model the conductor size selection (CSS) problems such as: conductor's economic life, discount rate, cable and installation costs and type of circuit (overhead or underground) [2]. Dynamic programming approach was utilized to solve the CSS problem in [3]. They presents models to represent feeder cost, energy loss and voltage regulation as a function of a conductor cross-section. In [4], the conductor size selection performed with consideration of financial and engineering criteria in the feeder. In [5] and [6] the CSS problem is solve using heuristic methods. Reference [5] uses a selection phase by means of economic criteria, followed by a technical selection using a sensitivity index that seeks to ensure a feasible operation of the EDS, whereas [6] presents a heuristic method using a novel sensitivity index for the reactive power injections. The heuristic methods are robust, easily applied; however, they normally converge to a local optimum solution. In some studies, a linear approximation in the calculation of power losses or voltage regulation is considered 
[7], while other approximates the load as a constant current model [3]. In [7], a mixed integer linear model for the problem of conductor selection size in radial distribution systems is presented. In this model, the behavior of the power type load is assumed to be constant. Several studies have used evaluative techniques to solve the CSS problem [8]-[10]. In [11] the optimal CSS placement is solved using a genetic algorithm.

In this paper, optimal type of conductor selection is proposed for planning radial distribution systems using different evolutionary algorithms, genetic algorithm (GA). The objective is minimizing the overall cost of annual energy losses and depreciation on the cost of conductors and reliability in order to improve productivity with considering the maximum current carrying capacity and acceptable voltage levels. Moreover, we utilize the BackwardForward sweep method which is simple, flexible, reliable, and didn't need Jacobian matrix and its inverse and have high convergence speed.

\section{Optimal conductor size selection}

The conductor size selection problem involves determining the optimal conductor configuration for a radial distribution system, using a set of types of conductors. Each type of conductor has the following characteristics: 1) resistance per length, 2) reactance per length, 3) maximum current capacity, 4) cross-sectional area and 5) building cost per length.

\section{Power Flow Analysis Method.}

The methods proposed for solving distribution power flow analysis can be classified into three categories: Direct methods, Backward-Forward sweep methods and Newton-Raphson (NR) methods. The Backward-Forward Sweep method is an iterative means to solving the load flow equations of radial distribution systems which has two steps. The Backward sweep, which updates currents using
Kirchhoff's Current Law (KCL), and the Forward sweep, which updates voltage using voltage drop calculations [12].

The Backward Sweep calculates the current injected into each branch as a function of the end node voltages. It performs a current summation while updating voltages. Bus voltages at the end nodes are initialized for the first iteration. Starting at the end buses, each branch is traversed toward the source bus updating the voltage and calculating the current injected into each bus. These calculated currents are stored and used in the subsequent Forward Sweep calculations. The calculated source voltage is used for mismatch calculation as the termination criteria by comparing it to the specified source voltage. The Forward Sweep calculates node voltages as a function of the currents injected into each bus. The Forward Sweep is a voltage drop calculation with the constraint that the source voltage used is the specified nominal voltage at the beginning of each forward sweep. The voltage is calculated at each bus, beginning at the source bus and traversing out to the end buses using the currents calculated in previous the Backward Sweep [12].

\section{Objective Function}

The objective is selection of conductor's size from the available size in each branch of the system which minimizes the sum of depreciation on capital investment and cost of energy losses and ... reliability while maintaining the voltages at different buses within the limits. In this case, the objective function with conductor $c$ in branch $i$ is written as

$$
\begin{aligned}
& \operatorname{Min} f(i, c)=w 1 * C E(i, c)+w 2 \\
& * D C I(i, c)+w 3 * F_{E N S}(i) \\
& \text { Subject to } \\
& \begin{array}{r}
V \min \leq|V i| \leq V \max \quad i \\
=1,2,3, \ldots, n \\
|I j| \leq \operatorname{Imax} \quad j \\
=1,2,3, \ldots, n-1
\end{array}
\end{aligned}
$$

Where CE (i,c) is the Cost of Energy Losses and $F_{E N S}(i)$ is the cost of energy not 
supplied and DCI $(i, c)$ is Depreciation on Capital Investment of $c$ conductor type of $i$ th branch, $\mathrm{n}$ is buss number, $\mathrm{i}$ is the branch number and $\mathrm{w}$ is the weighting factor[13]. The annual cost of loss in branch $i$ with conductor type $k$ is,

$$
C E(i, c)=P L(i, c) *\{K P+K E * \delta * T\}
$$

Where $K_{\mathrm{p}}$ is annual demand cost due to Power Loss $(\$ / \mathrm{kW}), \mathrm{K}_{\mathrm{E}}$ is annual cost due to Energy Loss $(\$ / \mathrm{kWh}), \delta$ is Loss factor, ( PL $(\mathrm{i}, \mathrm{c})$ ) is real Power Loss of branch $i$ under peak load conditions with conductor type $c$ and $T$ is the time period in hours $(8760$ hours). Depreciation on capital investment is given as

$$
\operatorname{DCI}(i, c)=\gamma * A(c) *\{C c+L i\}
$$

Where $\gamma$ is Interest and depreciation factor, $\mathrm{C}_{\mathrm{c}}$ is cost of type conductor $(\$ / \mathrm{km}),\left(\mathrm{A}_{\mathrm{c}}\right)$ is cross-sectional area of $c$ type conductor and $\mathrm{L}_{\mathrm{i}}$ is length of branch $\mathrm{i}(\mathrm{km})$.

$$
\begin{aligned}
F_{E N S}(i)=\frac{h}{8760} & \\
& \times \sum_{i} U_{i} \times P L_{i} \\
& \times \text { Cost_Shed }_{i}
\end{aligned}
$$

Where $U_{\mathrm{t}}$ : $\mathrm{i}$ mean outage times a year (hour/year); Cost_Shed ${ }_{i}$ : Cost of outage time $(\$ / \mathrm{KWh})$. Average time to confirm any of the loads of the network is obtained from the following equation

$$
U_{i}=\sum_{j} \lambda_{i j} \times r_{j}
$$

Where $\lambda_{i j}$ : Number of failures per year for equipment failures that result in lost time, $i$ is the $\mathrm{j} . r_{j}$ : the average time required to fix your equipment after each fault $j$ (hour).

\section{Genetic Algorithm}

GA's are generalized search algorithms based on the mechanics of natural genetics [14]. GA maintains a population of individuals that represent the candidate solutions to the given problem. Each individual in the population is evaluated to give some measure to its fitness to the problem from the objective function. GA's combine solution evaluation with stochastic operators namely, selection, crossover and mutation to obtain optimality. The flow chart of proposed GA is depicted in Fig. 1.

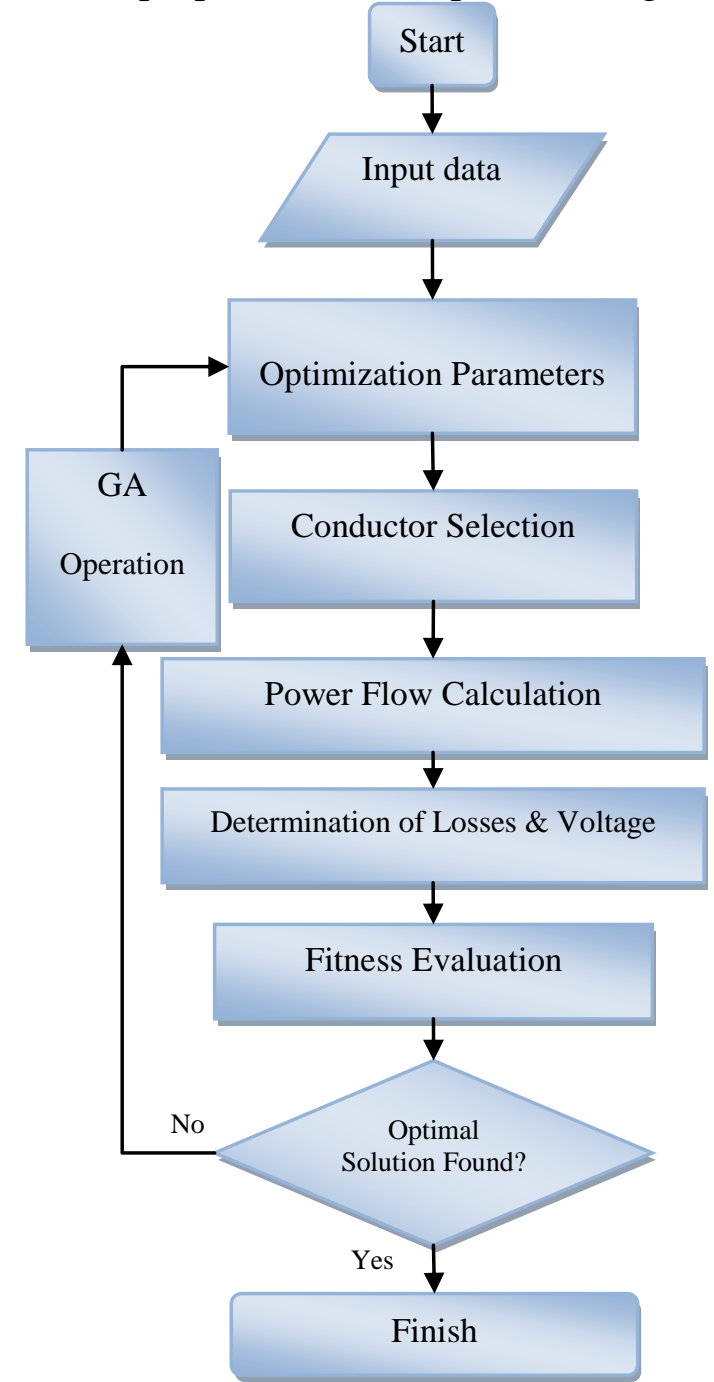

Fig 1: Flowchart of the proposed GA algorithm

\section{Tests and Results}

Simulations are carried out on 69-bus radial distribution network using GA approach in order to show the accuracy as well as the efficiency of the proposed solution technique. The single line diagram for proposed radial distribution systems is shown in Fig. 2. The base values of the system are taken as $20 \mathrm{kV}$ and 20MVA. The properties of the new conductors used in the analysis of this system are given in Table 1 . 
The total connected load on the system is $2550 \mathrm{KVA}$ and the peak demand for the year is $2120 \mathrm{KVA}$ at a PF of $0.8 \mathrm{lag}$. The other parameters used in computation process are: $\mathrm{KP}=1.04(\$ / \mathrm{kW}) ; \mathrm{KE}=0.012$ (\$/kWh).

Table 1: Conductor properties

\begin{tabular}{|c|c|c|c|c|c|}
\hline Type & $\begin{array}{c}\mathrm{R} \\
{[\Omega / \mathrm{km}]}\end{array}$ & $\begin{array}{c}\mathrm{X} \\
{[\Omega / \mathrm{km}]}\end{array}$ & Cmax $[\mathrm{A}]$ & $\mathrm{A}[\mathrm{mm} 2]$ & Cost $[\$ / \mathrm{m}]$ \\
\hline Hyena & 0.1576 & 0.2277 & 550 & 126 & 0.74 \\
\hline Dog & 0.2712 & 0.2464 & 440 & 120 & 1.25 \\
\hline Mink & 0.4545 & 0.2664 & 315 & 70 & 0.75 \\
\hline
\end{tabular}

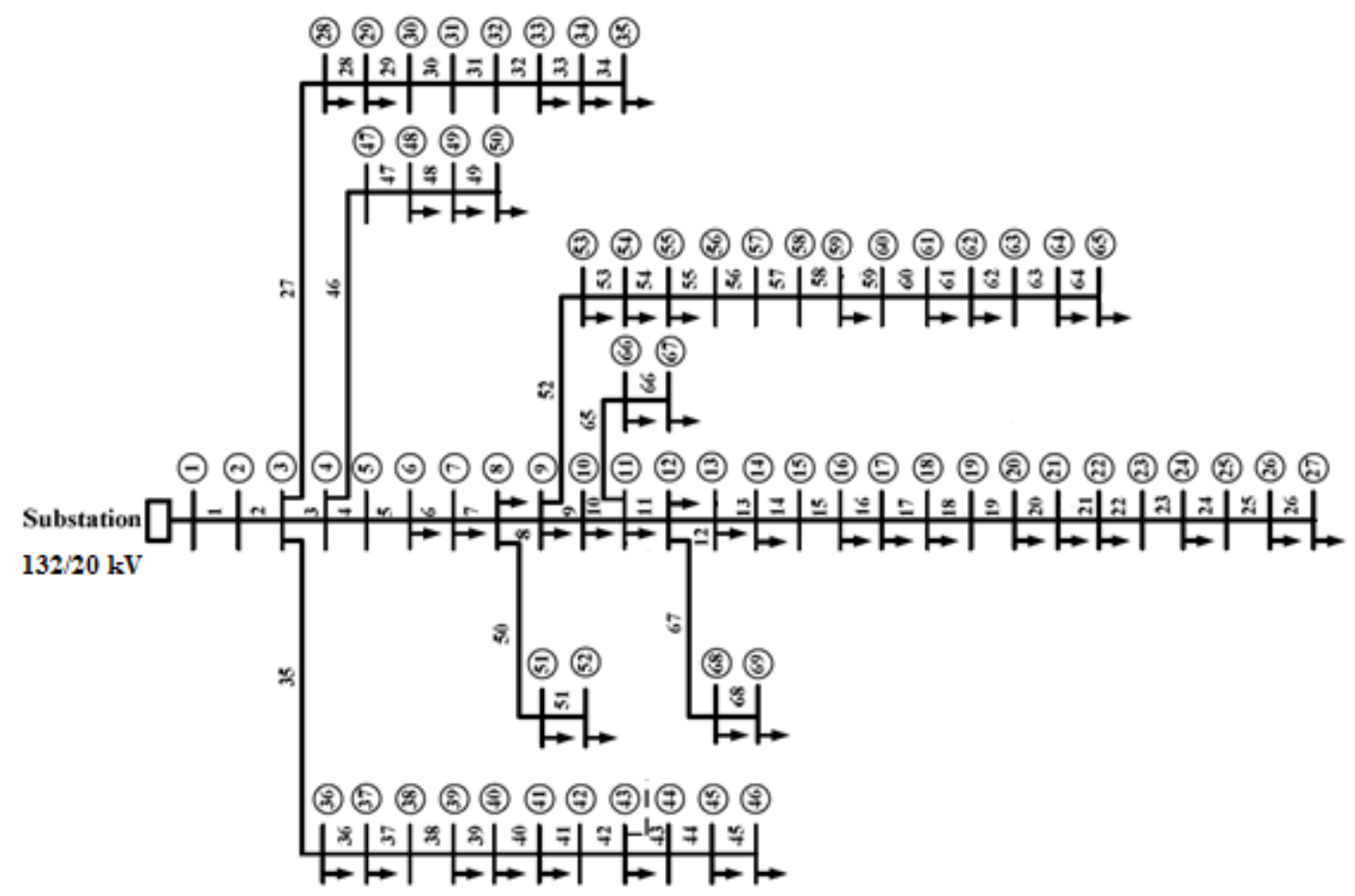

Fig 2: Single line diagram for a 69-bus radial distribution system

The parameters used in genetic algorithm (GA) are: Number of Decate is 33; Population size is 100; Number of Empire 10; Revolution rate is 0.1 . Also, loss factor, which represents adequately the energy losses for the load level in terms of the maximum power losses are selected. The results of conductor selection are shown in Table 2.
Table 2: Conductor selection results

\begin{tabular}{|c|c|c|}
\hline $\begin{array}{c}\text { Conductor } \\
\text { Design Method }\end{array}$ & Type & Branch Number \\
\hline \multirow{3}{*}{ Conventional } & Hyena & From 1 to 26 \\
\cline { 2 - 3 } & Dog & Rest of 68 branches \\
\cline { 2 - 3 } & Mink & ---- \\
\hline \multirow{3}{*}{ GA Based } & Hyena & $20,21,28,38,43$ \\
\cline { 2 - 3 } & Dog & --- \\
\cline { 2 - 3 } & Mink & Rest of 68 branches \\
\hline
\end{tabular}

The voltage profile and Power loss in the system after GA implementation is compared with Conventional conductor design and depicted in Fig. 3 and Fig. 4. The total power loss for different conductors 
selections depicted in Fig. 5. It can be seen that the voltage profile achieved by GA optimization algorithms are almost the same while having better improvement in compare with Conventional method. Moreover, a decrease in peak power loss based on peak power loss profiles is illustrated. The costs based on conductor selection are compared in Table 3. The real power loss reductions are $606.7364 \mathrm{~kW}$, which is approximately $5.6 \%$ in compare with the Conventional design for GA respectively. Proceedings in a similar manner, the total cost reduction (sum of annual cost of power loss and depreciation on capital investment cost) are obtained $30 \%$ for GA respectively.

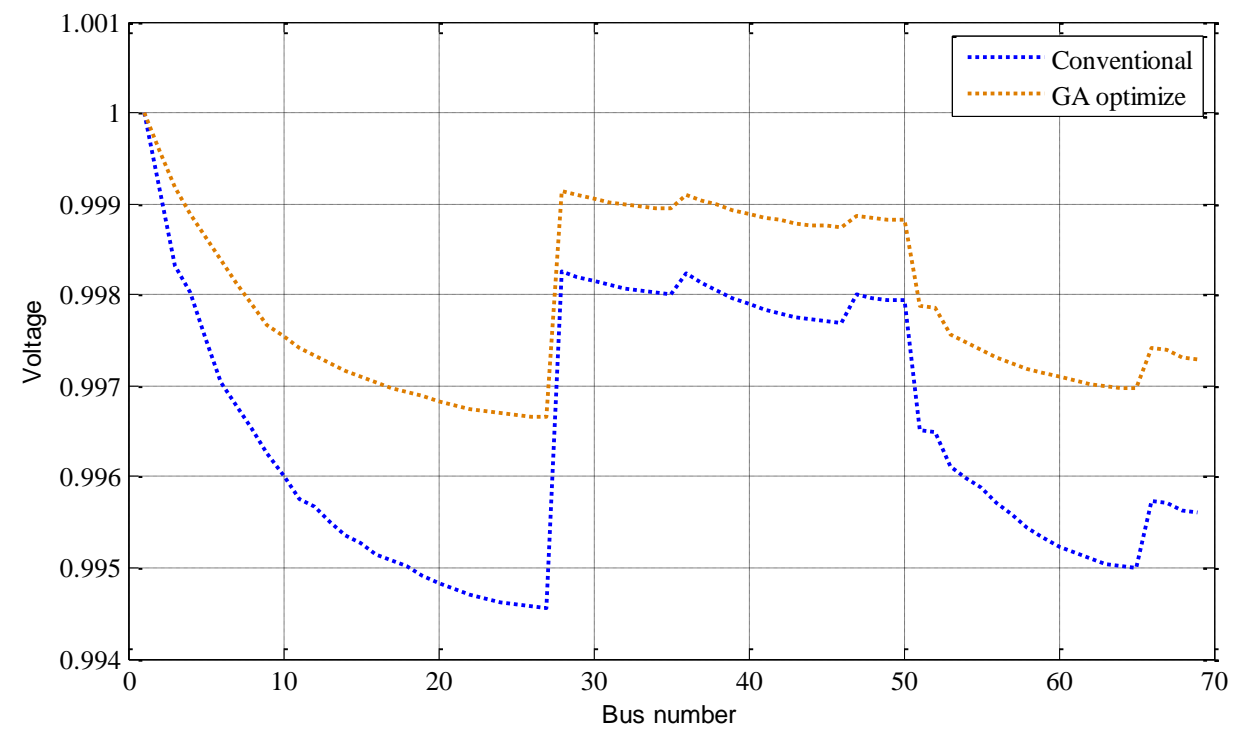

Fig 3: Voltage profiles of 69-bus system

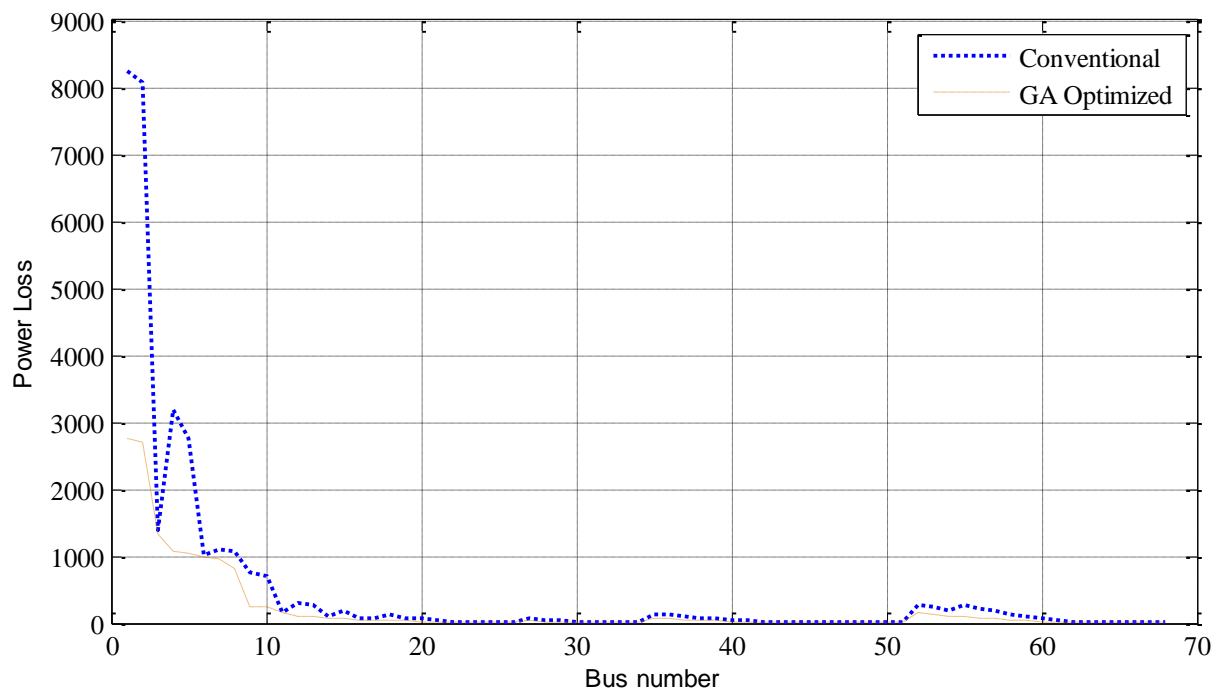

Fig 4: Peak power loss profiles in each branch 


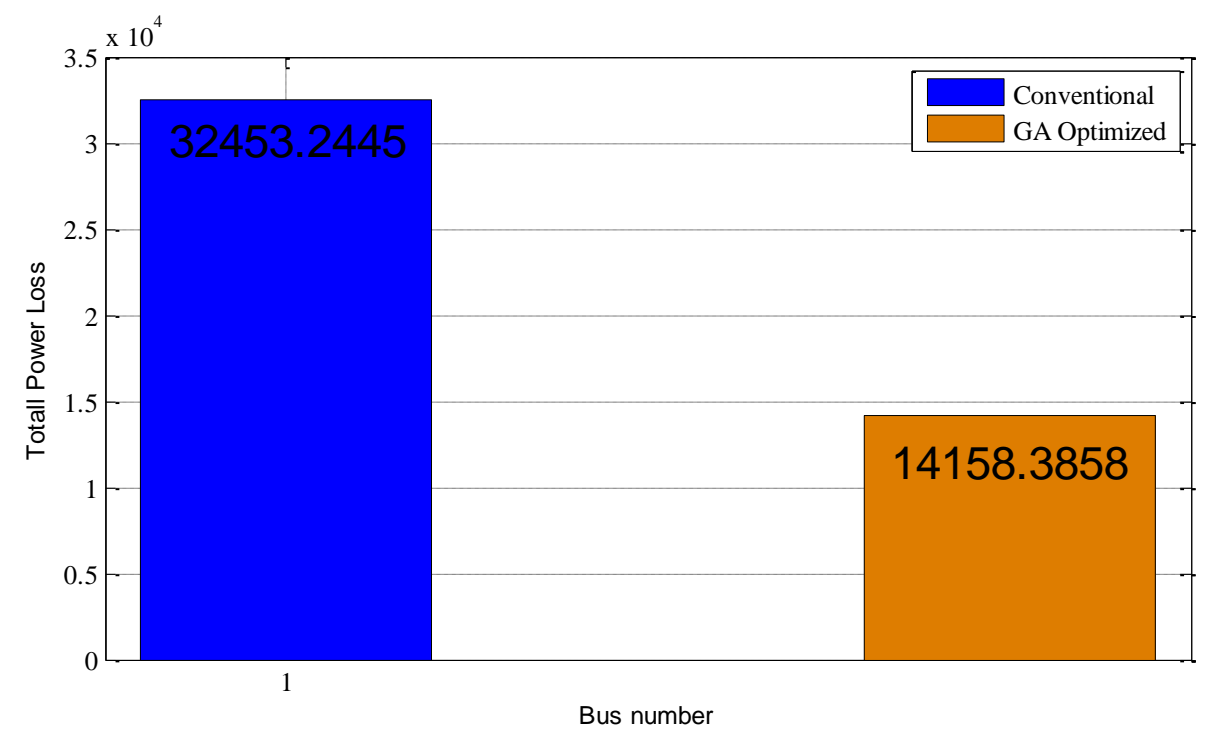

Fig 5: Total power loss for different conductor selections method

Table 3: Obtained Loss results

\begin{tabular}{|c|c|c|}
\hline & $\begin{array}{c}\text { Total Loss } \\
{[\mathrm{W}]}\end{array}$ & $\begin{array}{c}\text { Total Cost } \\
{[\$]}\end{array}$ \\
\hline Conventional & 32453.24452 & 18882.2 \\
\hline GA Based & 14158.38579 & 7571.5 \\
\hline
\end{tabular}

\section{Conclusion}

Optimal selection of conductor type for planning radial distribution systems using evolutionary approaches is presented with the objective to minimize the overall cost of annual energy losses and depreciation on the cost of conductors and the cost of energy not supplied in order to improve productivity. The power losses, voltage magnitude, and current flow magnitudes are calculated using the Backward-Forward sweep method.

The performance of the proposed evolutionary approaches (GA) in comparison with a conventional method is investigated using a 69-bus radial distribution network. The power loss reduction and voltage profile improvement has been successfully achieved which demonstrate the effectiveness of the proposed approaches. The results offer potential of using GA for improving plant productivity and economy.

\section{References}

[1] M. Mozaffari Legha, (2011) Determination of exhaustion and junction of in distribution network and its loss maximum, due to geographGAl condition, MS.c Thesis. Islamic Azad University, Saveh Branch, Markazi Province, Iran.

[2] G. J. Anders, M. Vainberg, D. J. Horrocks, S. M. Foty, J.Motlis, and J. Jarnicki, Parameters affecting economic selection of cable sizes," IEEE Trans. Power Del., vol. 8, no. 4, pp. 1661-1667, Oct. 1993.

[3] M. Ponnavaikko and K. S. Prakasa, "An approach to optimal distribution system planning through conductor gradation," IEEE Trans. Power App. Syst., vol. PAS101, no. 6, pp. 1735-1742, Jun. 1982.

[4] S. Mandal and A. Pahwa, "Optimal selection of conductors for distribution feeders," IEEE Trans. Power Syst., vol. 17, no. 1, pp. 192-197, 2002.

[5] Z. Wang, H. L. Yu, X.Wang, and H. Song, "A practGAl approach to the conductor size selection in planning radial distribution systems," IEEE Trans. Power Del., vol. 15, no. 1, pp. 350-354, Jan. 2000. 
[6] H. Zhao, Z. Wang, D. C.Yu, L. Zhou, andX. Chen, "Integratedmethodology of reactive planning and conductor sizing in radial distribution," in Proc. 2005 Power Engineering Society General Meeting, San Francisco, CA, Jun. 12-16, 2005, pp. 280285.

[7] M. J. Rider, M. Lavorato, R. Romero, "Optimal Conductor Size Selection and Reconductoring in Radial Distribution Systems Using a Mixed-Integer LP Approach", Power Systems, IEEE Transactions on, (doi: 10.1109/TPWRS.2012.2201263),2012

[8] F. Mendoza, D. Requena, J. L. BernalAgustin, and J. A. Dominguez- Navarro, "Optimal conductor size selection in radial power distribution systems using evolutionary strategies," in Proc. IEEE/PES Tranmission \& Distribution 2006 Latin AmérGA, Venezuela, 15-18, 2006, pp. 0105.

[9] R. Ranjan, A. Chaturvedi, P. S. Solanki, and D. Das, "Optimal conductor selection of radial distribution feeders using evolutionary programming," in Proc. 2003 IEEE Region 10 Conf. Convergent Technologies for the Asia-Pacific
(TENCON 2003), Bangalore, India, 15-17, 2003, vol. 1, pp. 456-459.

[10] R. S. Rao, "Optimal conductor selection for loss reduction in radial distribution systems using differential evolution,” Int. J. Eng. Sci. Technol., vol. 2, no. 7, pp. 2829-2838, Jul. 2010.

[11] M. Vahid, N. Manouchehr, S. D. Hossein, and A. Jamaleddin, "Combination of optimal conductor selection and capacitor placement in radial distribution systems for maximum loss

reduction," in Proc. 2009 IEEE Int. Conf. Industrial Technology, Gippsland, Australia, Feb. 10-13, 2009, pp. 01-05.

[12] N. Medina, M.M. Qi, L. Butler-Purry, K.L. A Three Phase Load Flow Algorithm for Shipboard Power Systems (Sps), 2003. [13] T. Gönen, Electric Power Distribution Systems Engineering. New York: McGrawHill, 1986.

[14] D.E. Goldberg,' 'Genetic Algorithms in search, optimization and Machine learning." Addison -Wesley, Reading M.A, 1989.

[15] E. Atashpaz-Gargari, C.Lucas, 'Imperialist competitive algorithm: an algorithm for optimization inspired by imperialistic competition". IEEE CongrEvolComput 2007:466,1-7. 